\title{
Entrepreneurial orientation and the business performance of SMEs: a quantitative study from the Netherlands
}

\author{
Sascha Kraus • J. P. Coen Rigtering • Mathew Hughes • \\ Vincent Hosman
}

Received: 22 December 2010/Accepted: 23 March 2011/Published online: 13 April 2011

(C) The Author(s) 2011. This article is published with open access at Springerlink.com

\begin{abstract}
Entrepreneurial Orientation (EO) is often mentioned as an antecedent of growth, competitive advantage and superior performance, and prior empirical research has often shown a positive relationship between EO and performance appears to exist. However, an important question that remains unanswered is what effect EO might have on firm performance during periods of economic crisis, and the severe environmental turbulence that accompany such crises. This research is a first investigation towards the effects of EO on the performance of small and medium sized firms during the current global economic crisis. In this study we use the multidimensional model of EO and test a series of hypotheses pertaining to its performance effects using survey data gathered from 164 Dutch SMEs. The present research shows that proactive firm behavior positively contributes to SME performance during the economic crisis. We further show that innovative SMEs do perform better in turbulent environments, but those innovative SMEs should minimize the level of risk and should take action to avoid projects that are too risky.
\end{abstract}

Keywords Entrepreneurial orientation - Economic crisis - Environment . Proactiveness - Innovativeness - Risk-taking - Growth - SME performance · Netherlands

\footnotetext{
S. Kraus $(\bowtie)$ - J. P. C. Rigtering · V. Hosman

Utrecht University School of Economics (USE), Chair of Entrepreneurship, Janskerkhof 12, 3512 BL Utrecht, Netherlands

e-mail: s.kraus@uu.nl

S. Kraus

University of Liechtenstein, Fürst-Franz-Josef-Strasse, 9490 Vaduz, Liechtenstein

M. Hughes

Nottingham University Business School, University of Nottingham, Jubilee Campus,

Wollaton Road, Nottingham NG8 1BB, UK
} 
JEL Classification $\quad$ L25 $\cdot$ L26 $\cdot$ M10

\section{Introduction}

Entrepreneurial activities are increasingly regarded as important to firms, but in today's complex global economy, entrepreneurship has become even more crucial towards obtaining a sustainable competitive advantage (Wiklund and Shepherd 2003). Due to globalization, small and medium sized enterprises (SMEs) face increasing pressure from competition from across the world. When compounded with the changing sophistication of customers worldwide it becomes apparent that SMEs face increasing difficulty in maintaining and improving business performance in time, unless they can actively manage these pressures. SMEs are encouraged to implement an entrepreneurial mindset to recognize the threats and opportunities in the environment of the firm in order to make sure that the firm will continue to exist in the future (Krueger 2000). In periods of economic and environmental turbulence, it becomes even more apparent that firms face particularly high levels of market instability and complex business uncertainty that obliges firms to act upon such change (Grewal and Tansuhaj 2001; Lin and Carley 2001). A firm level response is therefore needed (Chattopadhyay et al. 2001).

Environmental turbulence can have a significant impact on the viability of a firm such that it is critical for managers to understand and effectively manage these events, as well as for scholars to determine what elements might explain the business performance difference between those firms rising and falling in complex environmental conditions (Grewal and Tansuhaj 2001). In scholarly literature (e.g., Zahra 1991; Wiklund and Shepherd 2005; Rauch et al. 2009), politics (e.g., Balkenende 2007; Dalmeijer 2009) and popular science (e.g., Collins 2001), the current school of thought posits that entrepreneurship is an antecedent of growth, sustainable competitive advantage and excellence. This is particularly true for enterprises operating in rapidly changing and competitive environments (e.g., Zahra and Covin 1995; Chandler et al. 2000; Antoncic and Hisrich 2001) and 'hostile' environments (Covin and Slevin 1989).

The questions we propose herein are: (1) could entrepreneurship explain superior business performance during a period of considerable market turbulence? And, (2) how might any effects resulting from elements of a firm's entrepreneurial orientation change in light of market turbulence? The goal of this article then is to investigate the influence of entrepreneurship on SME business performance when such firms face acute market uncertainty and instability. To achieve this we collected data during 2009, a year that was entrenched in the economic turbulence brought on by the collapse of the global financial sector. We do not seek to address the relative advantages of entrepreneurship in crisis and non-crisis times, rather, we seek to more adequately examine the impact of entrepreneurship on the business performance of SMEs when the skills associated with entrepreneurship (e.g., ability to manage uncertainty; innovate to meet emerging opportunities and threats; tolerate risk) would theoretically be called for. 
Surprisingly few studies have examined the firm capabilities and conditions necessary for extreme environmental and market turbulence. Grewal and Tansuhaj (2001) in their analysis of the Asian financial and economic crisis from the late 1990s found that firms that could achieve and maintain strategic flexibility (defined as the organizational ability to respond promptly in a proactive and reactive manner to market threats and opportunities) achieved superior business performance. On the basis that an entrepreneurial orientation might synthesize such strategic flexibility, we aim to contribute not just to our understanding of the consequences of entrepreneurial orientation, but also into the historical conversation on firm capabilities needed to manage situations of complex environmental and market turbulence. Doing so will also help further our appreciation of the value of entrepreneurial orientation to firms.

\section{Theoretical framework}

\subsection{Entrepreneurship}

The term entrepreneurship has been used for decades, yet to this day there is little consensus about its definition (Williams et al. 2010). Many perspectives can be found in the literature but the most common themes include: creation of wealth, creation of enterprise, creation of innovation, creation of change, creation of employment, creation of value, and creation of growth (Morris et al. 2008). Considerable effort has recently been put into developing a uniform definition. For example, Morris et al. (2008) performed a keyword analysis of the definitions of entrepreneurship found in relevant literature and found 18 keywords used at least five times. Subsequently, they defined entrepreneurship according to the definition of Stevenson and Jarillo-Mossi (1986) that "entrepreneurship is a process of creating value by bringing together a unique package of resources to exploit an opportunity" (p. 10), because this definition captured all the core keywords of entrepreneurship encountered in their research.

This definition does not limit the kind of organizations in which entrepreneurial activities may appear. Indeed, entrepreneurial behaviour is not only possible in new ventures, but also in firms regardless of their size and age (Kraus et al. 2011). The entrepreneurial activities of existing and established firms have for example been described as corporate entrepreneurship (Burgelman 1983; Zahra 1993), entrepreneurial orientation (Lumpkin and Dess 1996; Wiklund 1999), or intrapreneurship (Antoncic and Hisrich 2001, 2004).

Within the present article, the entrepreneurial activities of an established firm will be referred to as its 'Entrepreneurial Orientation' (EO). EO refers to the decision-making styles, practices, processes and behaviours that lead to 'entry' into new or established markets with new or existing goods or services (Lumpkin and Dess 1996; Wiklund and Shepherd 2003; Walter et al. 2006). This definition of EO is consistent with the view that EO leads to new market entry in either new or existing markets, but also explicitly recognizes that this can be achieved with either new or existing goods or services. In a manner of speaking then, a firm that is 
entrepreneurial oriented ventures into new or existing markets, with innovations that are either based on new or existing products and services, in a manner that is appreciative of the uncertainty and incurs risk in doing so.

The relationship between EO and business performance has been researched intensively. The entrepreneurship research started in the United States of America (USA) and until the year 2000 most studies are conducted in this country setting. Later, researchers performed studies in, among other places, Sweden (Wiklund and Shepherd 2003, 2005), Slovenia (Antoncic and Hisrich 2001, 2004; Antoncic 2006), South Africa (Goosen et al. 2002), China (Chen et al. 2005), Greece (Dimitratos et al. 2004), Finland (Jantunen et al. 2005), Germany (Walter et al. 2006), Vietnam and Thailand (Swierczek and Ha 2003), Netherlands (Kemelgor 2002; Stam and Elfring 2008), United Kingdom (Hughes and Morgan 2007) and Turkey (Kaya 2006). Among the legacy of studies that have taken place over the years, the business performance consequences of EO have not always been clear.

Recently, Rauch et al. (2009) performed a meta-analysis of the relationship between EO and business performance. Their study included 51 articles and showed a significant positive relationship between EO and business performance. The control variable for cultural differences between continents included by the authors turned out to be statistically insignificant, meaning that the relationship between EO and business performance is "of similar magnitude in different cultural contexts" (Rauch et al. 2009, p. 779). Of the 51 papers included, only four other studies reported mixed or no significant findings. Slater and Narver (2000) did not find a significant relation between entrepreneurial orientation and business performance at all. Swierczek and Ha (2003) found only a partial positive relationship and Walter et al. (2006) found that EO is not directly related with business performance. Covin and Slevin (1989) found that there is a larger positive effect of entrepreneurship on business performance in hostile environments, while there seems to be no significant relation in benign environments. Also, other researchers have included environment as a moderator or as a control variable in their models. Lumpkin and Dess (2001) found environmental hostility to be a significant moderator in the relationship between EO and firm profitability. Wiklund and Shepherd (2003) use environmental munificence and heterogeneity as control variables within their research on knowledge-based resources and EO. Within their research, environmental munificence emerged as a significant control variable.

As our study, the research executed by Kemelgor (2002) and Stam and Elfring (2008) is also performed in the Netherlands. Kemelgor (2002) performed a comparative analysis of the differences in EO between Dutch companies and their direct competitors from the USA. Their findings showed a positive relationship between EO and all of the performance measures incorporated in their study (number of new innovations, number of patents received and return on sales) for the US firms. In the Netherlands, however, this relationship was only proven to be significant for the number of patents received and return on sales. Furthermore, the significance is lower (5\% compared to $1 \%$ ) and, more importantly, the relationship is weaker. Kemelgor (2002) suggests two possible reasons for these differences. The first is the differences in the culture towards entrepreneurship between the Netherlands and the USA. A second reason, according to Kemelgor (2002), is the 
existence of a Work Council in Dutch companies, required by Dutch law, where employees can discuss organizational operations. This was argued to lead to a situation in which "participation [in the firm's EO] is a social obligation rather than a vehicle to truly impact business performance" (2002, p. 82).

In theory, for an entrepreneurial orientation to affect firm-wide behaviour and be adopted as an organizational mindset, it is necessary for employees across the firm to participate in the entrepreneurial actions captured within an EO on a voluntary basis. Lumpkin and Dess (1996) for example commented on the extent to which employees were involved in the use of entrepreneurial activity as supported (or otherwise) by the culture and structure of the firm. In corporate entrepreneurship research for example, Ireland et al. (2009) posited that buy-in into an entrepreneurial vision for the business depends on "[t]op-level managers [working] to create organizational architectures in which entrepreneurial initiatives flourish without their direct involvement" (p. 30). Ireland et al. (2009), similar to Lumpkin and Dess (1996), suggest that the structure and culture of the firm should encourage "a proclivity toward such qualities as decentralized decision making, low formality, wide spans of control, expertise- (vs. position)-based power, process flexibility, free-flowing information networks, and loose adherence to rules and policies... [g]reater mechanization implies the opposite" (p. 31), as well as "being highly committed to work and willing to accept responsibility for outcomes resulting from it” (p. 31). Following Kemelgor's (2002) logic, Dutch firm might be restricted form putting in place such structural and cultural conditions owing to the nature of Work Councils demarcating employees and management. Similar points can be drawn from the work of Hornsby et al. (2002) in that employee involvement shapes their understanding of top managers' willingness to facilitate and support entrepreneurial behaviour. When coupled with a voluntary acceptance of work discretion and autonomy, the EO of the firm would be expected to be more effective.

Stam and Elfring (2008), on the other hand, performed a different kind of analysis than Kemelgor (2002). They investigated whether and how the founding team's intra- and extra-industry networks influence the performance of new ventures. From their research, it can be concluded there is a strong relationship between EO, measured by its network, and performance, but that it is weakened in firms with low social capital.

Wiklund and Shepherd (2005) concluded after reviewing previous research that "the differences [among study findings] reflect the fact that EO may sometime, but not always, contribute to improved performance" (p. 2). The meta-analysis of Rauch et al. (2009) nonetheless leads to an aggregate conclusion that an overall significant relationship between EO and business performance exists. Still, what these studies do suggest is that the value of EO might vary and so it is necessary for researchers to better appreciate the context in which EO is used by firms (e.g., Stam and Elfring 2008).

\subsection{Dimensions of entrepreneurial orientation}

According to Wiklund (1999), most researchers agree that EO is a combination of three dimensions: innovativeness, proactiveness and risk-taking. Indeed, many 
studies (e.g., Covin and Slevin 1989; Naman and Slevin 1993; Zahra and Garvis 2000; Kemelgor 2002) follow this three dimensional model created by Miller (1983). Research by Stetz et al. (2000), Kreiser et al. (2002) and Hughes and Morgan (2007) have shown that the dimensions can vary independently from each other and should also be allowed to vary (as proposed by Lumpkin and Dess 1996). However, only a few researchers allow the dimensions described above to vary within their model and create a truly multidimensional EO model. The discussion lies in not whether the dimensions can differ from each other but is based on the belief that an entrepreneurial firm should score on all three dimensions (Covin et al. 2006). This issue is an important one because Lumpkin and Dess (1996) posited that not all of the dimensions of EO would directly or positively affect business performance under different circumstances. Thus, to more fully appreciate the influence of EO, assessing the relative impact of each dimension of EO separately is arguably necessary.

Schumpeter (1942) was one of the first to point out the importance of innovation in the entrepreneurial process. He called the disruptive innovation process 'creative destruction', a process that occurs when wealth is created by the introduction of new products or services that disrupt the current market and causes a shift in the use of resources. Extrapolating this view further, the EO dimension of innovativeness is about pursuing and giving support to novelty, creative processes and the development of new ideas through experimentation (Lumpkin and Dess 1996).

The second dimension is proactiveness. Proactiveness refers to processes which are aimed at "seeking new opportunities which may or may not be related to the present line of operations, introduction of new products and brands ahead of competition and strategically eliminating operations which are in the mature or declining stages of the life cycle" (Venkatraman 1989, p. 949). Indeed proactiveness concerns the importance of initiative in the entrepreneurial process. A firm can create a competitive advantage by anticipating changes in future demand (Lumpkin and Dess 1996), or even shape the environment by not being a passive observer of environmental pressures but an active participant in shaping their own environment (Buss 1987).

The third dimension, risk-taking, is often used to describe the uncertainty that follows from behaving entrepreneurially. Entrepreneurial behaviour involves investing a significant proportion of resources to a project prone to failure. The focus is on moderated and calculated risk-taking instead of extreme and uncontrolled risk-taking (Morris et al. 2008) but the value of the risk-taking dimension is that it orients the firm towards the absorption of uncertainty as opposed to a paralyzing fear of it.

Lumpkin and Dess (1996) posited that the dimensions of EO can vary independently and proposed that each dimension might not necessarily contribute to business performance in each instance. Despite the caution advocated by Lumpkin and Dess (1996), most studies have used a combined measure of risk taking, innovativeness and proactiveness to capture EO. For example, in the metaanalysis performed by Rauch et al. (2009), only $25 \%$ of the articles included in their analysis use a multidimensional model in which the dimensions of EO can vary from each other. The authors conclude that the dimensions are of equal value to the 
EO-performance relationship and therefore can be indexed into one variable. Other studies like Yoo (2001) and Covin et al. (2006) confirm this, but some studies suggest otherwise (e.g., Hughes and Morgan 2007; Swierczek and Ha 2003). Swierczek and Ha (2003) for example found in a sample of firms from Vietnam and Thailand, that the EO dimensions of proactiveness and innovativeness were positively related to firm performance, while risk-taking was not. Hughes and Morgan (2007) show similar results in the UK while investigating incubating firms. In their sample, both risk taking and innovativeness is not significantly related to customer performance.

In concurrence with the work of Covin et al. (2006), who argue that including the subdimensions to the model could lead to new theories, a multidimensional model with all three subdimensions described above will be tested. While the research evidence on the effects of the subdimensions of EO are far less clear than those that have assessed their combined effect as a single EO construct, the broad thrust of the literature is that EO should be associated with improvements in the business performance of firms in general (see e.g., Lumpkin and Dess 1996; Rauch et al. 2009). Indeed, over time a firm deploying an EO would be expected to develop a suite of skills (e.g., ability to manage uncertainty; ability to innovate to meet emerging opportunities and threats; ability to anticipate direction and nature of market change; ability to tolerate risk) that shape a firm entrepreneurship capability to further improve business performance. In line with results from earlier research on EO overall, research including separated dimensions and the high correlations between the dimensions, it is expected that all three dimensions are positively related to SME business performance. Thus, we hypothesize the following:

Hypothesis 1A There is a direct positive relationship between the EO dimension of innovativeness and SME business performance.

Hypothesis 1B There is a direct positive relationship between the EO dimension of proactiveness and SME business performance.

Hypothesis 1C There is a direct positive relationship between the EO dimension of risk-taking and SME business performance.

\subsection{Environment}

In their conceptual paper, Lumpkin and Dess (1996) argued that the characteristics of the environment might have a strong effect on the strength and direction of the relationship between entrepreneurial orientation and firm performance. Empirical research has found support for this view, proposing that the relationship of EO and firm performance is contingent upon the firm's external environment (e.g., Covin and Slevin 1989; Naman and Slevin 1993; Zahra 1993; Zahra and Covin 1995).

Uncertainty is one of the main characteristics of environmental and market turbulence. Miller (1988) stated that the dimensions of dynamism and unpredictability are "the key components of the overarching construct of uncertainty" (p. 291). Therefore 'unpredictability' and 'dynamism' will be used and incorporated in an overall scale typically called market turbulence (Miller and Friesen 1982). 'Dynamic' 
environments are described as markets in which products have a short life cycle, the level of industry innovation is high and customers' demands as well as competitors' actions are highly 'unpredictable' (Zahra 1993; Wiklund and Shepherd 2005).

Firms that invest in an EO could be expected to maintain and even improve business performance under conditions of high market turbulence market conditions because these firms tend to possess an ability to react to the constant shifts taking place in the environment by exploring and exploiting new opportunities. Firms with out an EO risk strategic paralysis when faced with change. The logic for this belief stems from the argument that EO drives exploration within the firm and allows the reconfiguration of resources and knowledge into better product-market solutions to meet anticipated change (Atuahene-Gima and Ko 2001; Hughes et al. 2007; Hughes and Morgan 2007). Firms that have not invested in building an EO may not be able to profit from changing conditions since they are unable to reconfigure their resources and knowledge. It is likely that the products of these firms move out of market demand resulting in lower business performance (Wiklund and Shepherd 2005), or lose competitiveness within the changing market (Atuahene-Gima and Ko 2001).

In the face of complex market turbulence, the skills associated with an EO, such as the ability to manage uncertainty, the ability to innovate to meet emerging opportunities and threats, the ability to anticipate direction and nature of market change, the ability to tolerate risk, would likely lead the managers of an entrepreneurially oriented firm to reframe and interpret events that result from market turbulence as opportunities for further business model change, growth and innovation, as opposed to threats that can only undermine the business. Indeed, Barr and Glynn (2004) found that a greater propensity towards uncertainty avoidance, which might be thought of as an antithesis to classic views of EO, has been associated with greater interpretation of strategically relevant events as threats as opposed to opportunities. Given that the skills engendered and embedded by an EO would be expected to shape a firm entrepreneurship capability in time (see Wiklund and Shepherd 2003, for treatment of EO as a firm rare resource or capability), such a capability should enable a firm to better manage market turbulence such that the firm ought to be able to capitalize when market turbulence is acute. As such, business performance would be expected to improve.

A contingency theory perspective of this kind suggests that the direction and strength of the EO-performance relationship might be influenced by market turbulence (see Luthans and Stewart 1977; Miller 1981). We suggest that, besides the direct effect on EO on business performance, innovativeness, risk-taking and proactiveness will be positive related to the business performance of SMEs in environments where the uncertainty caused by acute market turbulence is high. This expectation is consistent with prior research that has associated EO with superior business performance in hostile environments as opposed to benign environments. For example, Covin and Slevin (1989) found that EO was not directly related to firm performance but only the interaction term with environment; Miller (1988) found that in an uncertain environment, innovation was positively related to business performance; and Zahra's (1993) empirical research found a strong positive relationship between business performance and entrepreneurship in firms operating in dynamic growth environments. We therefore postulate the following: 
Hypothesis 2A The relationship between innovativeness and SME business performance is moderated by market turbulence. Firms with higher levels of innovativeness perform better in environments with higher levels of turbulence.

Hypothesis 2B The relationship between proactiveness and SME business performance is moderated by market turbulence. Firms with higher levels of proactiveness perform better in environments with higher levels of turbulence.

Hypothesis 2C The relationship between risk-taking and SME business performance is moderated by market turbulence. Firms with higher levels of risk-taking perform better in environments with higher levels of turbulence.

\section{Research method}

\subsection{Sample}

Data was collected by means of an email survey from October 2009 until November 2009. Using a key informant approach (Kumar et al. 1993), the questionnaire was sent to the Chief Executive Officers (CEOs) of approximately 6,000 SMEs listed in a database of one of the biggest banks in the Netherlands. Due to new 'anti-spam' regulations in the Netherlands, no reminder was sent. Of those 6,000 SMEs, 201 responded and filled in the questionnaire, a response rate of nearly $3.5 \%$. Within the 201 respondents 37 entrees where dropped because these firms did not meet the criteria for SMEs set by the European Union (European Commission 2003), in casu quo firms employing less than 10 employees or employing more than 250 employees. This resulted in 164 valid responses for use in the statistical analysis.

The majority of respondents $(51.5 \%)$ are active in the service industry and $48.5 \%$ operate in the manufacturing industry. The average age of the firm is 43.34 years, with a standard deviation of almost 35 years. Most firms $-70.7 \%$ of the sample-fit in the category of 'small' firm, meaning 10-49 employees. Fewer firms-29.3\% of the sample-are 'medium' sized firms; employing 50-250 people. A short overview of all sample statistics can be found in Table 1 .

In line with the goal of this article to investigate the influence of entrepreneurship on SME business performance when such firms face acute market uncertainty and instability, or turbulence, the decision to collect data in 2009 can be considered an

Table 1 Overview sample statistics

\begin{tabular}{lc}
\hline Total number of returned questionnaires & 201 \\
Effective sample size & 164 \\
Percentage of firms employing 10-49 employees (small sized) & $70.7 \%$ \\
Percentage of firms employing 50-250 employees (medium sized firms) & $29.3 \%$ \\
Average firm age in years & 43.34 \\
Percentage of firms operating in the manufacturing industry & $51.5 \%$ \\
Percentage of firms operating in the service industry & $48.5 \%$ \\
\hline
\end{tabular}


appropriate one. The year 2009 saw many markets exposed to economic turbulence brought on by the earlier collapse of the global financial sector. This makes the 2009 time point appropriate to examine the impact of entrepreneurship on the business performance of SMEs.

\subsection{Measures}

\subsubsection{Entrepreneurial orientation}

A considerable amount of research exists into EO and its measurement. While some researchers have built their own measurement models, most studies have modified or used the original scales developed by Khandwalla (1977) or Miller (1983).

Until 2000 most research on EO had been carried out in the USA. Therefore most measurement models were developed for and tested only on US firms. Knight (1997) carried out research to test the reliability and validity of the ENTRESCALE abroad. This measurement scale is originally developed by Khandwalla (1977) and later refined by Miller and Friesen (1982) and Covin and Slevin (1986, 1989). After testing this measurement tool for entrepreneurial orientation on English and French speaking managers, the ENTRESCALE was found to be applicable to measure the level of entrepreneurship in firms abroad (Knight 1997). Kemelgor (2002) followed the same approach as Knight (1997) to test the applicability of the entrepreneurial orientation scale of Covin and Slevin (1986) in the Netherlands. His $t$ test showed no significant differences between the Dutch and English versions of the scale. Within the present research the scale developed by Covin and Slevin (1989) is used to measure the level of EO. The scale includes the three dimensions of EO discussed before: innovativeness, risk-taking and proactiveness. All scales are 7-point Likerttype scales in which respondents are obligated to choose between pairs of opposing statements.

\subsubsection{Environment}

The measurement scale developed by Miller and Friesen (1982) is used to measure the level of perceived market turbulence. This scale has been proven to be valid and reliable (e.g., Covin and Slevin 1989; Naman and Slevin 1993). The turbulence scale is a seven point Likert-type scale in which interviewees are obligated to choose between pairs of opposing statements.

\subsubsection{SME business performance}

The choice of indicators to measure business performance may influence the results of the relationship between EO and performance (Lumpkin and Dess 1996; Hughes and Morgan 2007). In extant empirical works, many indicators tend to be used. 'Performance' is regularly measured in one or a combination of the following three ways: perceived financial, perceived non-financial and archival financial (Rauch et al. 2009). 
Considering that most firms did not have archival performance numbers over 2009 available at the time of this study (conducted in 2009 itself so as to capture firms' EO at that time), perceived performance indicators are used. While perceived measures of a firm's performance can be disadvantageous in that they rely on a CEO's ability to accurately rate the objective financial performance of their firm with a subjective proxy of it, many studies have reported on the advantages of perceived performance measures as well. For example, Bamford et al. (2000) note that "it is quite common for entrepreneurs to refuse to divulge performance information to researchers, and, therefore, the accuracy of such data is questionable" (p. 255). Other researchers have focused on the accuracy and reliability of perceived performance measures. Wall et al. (2004) found across three different samples that subjective and objective were strongly positively associated demonstrating convergent validity in turn. Geringer and Hebert (1991) in a study of international joint ventures found there is little difference between subjective and objective measures of performance. Dess and Robinson (1984) found a strong association between subjective and objective performance measures in privately-held firms. Similar results in entrepreneurship research are reported by Sarkar et al. (2001) as they show a high correlation between perceived measures of performance and archival measures. These results are confirmed by the meta-analysis of Rauch et al. (2009), where no difference in the EO-performance relationship with perceived financial performance, perceived non-financial performance or archival financial performance was found. Furthermore Govindarajan (1988) notes that the use of multiple performance measure methods are permitted if there is reason to question the validity of the single method or in cases where single-measure objective data are not available (see also Dess and Robinson 1984). Thus, by using perceived performance methods the reliability and the validity of the research should hold firm.

Wiklund (1999) suggested that a measurement scale for SME business performance should have indicators for growth as well as for financial performance. In this study, performance measures based upon Wiklund and Shepherd (2005) are used. These scales are chosen because of their reliability and common use in the literature. The authors used five indicators to capture business performance: sales growth rate, employee growth, gross margin, profitability and cash flow. Within the present research, a 5-point Likert-type scale (ranging from 1 "extremely bad performance" to 5 "excellent performance") was used to rate the firm's financial performance on gross margin, profitability and cash flow. Unlike Wiklund and Shepherd (2005), who measure the growth of the firm at two different points in time, two growth measures are used in this study to directly assess the growth in both the number of employees and the growth in turnover. Respondents were asked to rate their firm's business performance compared to his or her assignment or expectations (measured on a 5-point Likert-type scale ranging from 1 "extremely bad performance" to 5 "excellent performance").

\subsubsection{Control variables}

Firm age, firm size and industry were used as control variables in the model. These control variables are commonly used in EO research (e.g., Zahra and Garvis 2000; Antoncic and Hisrich 2004; Stam and Elfring 2008;) as they can affect the resource 
base of the firm as well as firm behavior. Respondents are asked for the founding year of the firm to calculate firm age. Secondly, respondents were asked to indicate the number of employees from a selection of less than 10 (micro), 10-49 (small), 50-250 (medium) and more than 250 (large). Large and micro firms were removed from the analysis because they do not fit the EU definition of SMEs (10-250 employees), the target group for this study (European Commission 2003). The inclusion of firm size therefore served as an additional way of reducing sampling error. Thirdly the respondents were asked to state the industrial sector their firms operated into account for industry variation.

\section{Data analysis}

\subsection{Factor analysis}

An exploratory factor analysis was performed to test the multidimensionality of the EO concept and gauge construct validity. All independent composite constructs using multiple items were included in this analysis. We used a principal component analysis with Varimax rotation. The Kaiser Criterion (Kaiser 1960; eigenvalues >1) has been used to determine the number of factors. The scale items, factor loadings and fit statistics are reported in Table 2. Listwise deletion of all missing data led to 111 cases for use within the factor analyses. Since factor loadings are sensitive to sample size, the criteria set out by Stevens (1992) are used to determine if the different factor loading are significant. For a sample size of 100 cases or more, Stevens (1992) reports that factor loadings of .522 or larger can be considered to be significant. In order to assess the discriminant validity of the different items, a general rule of thumb is used that cross-loading should be larger than .300 . The results of the factor analyses showed that all items have highly significant loadings on their hypothesized latent variables, no significant loadings on other factors and sufficient cross-loadings ( $>.310$ ) All of the factors combined account for $64.00 \%$ of the total variance in the dataset. Both the chi-square for the measurement model $\chi^{2}$ (678.15; $d f=91 ; p=<.001)$ and the Kaiser-Maeyer-Olkin measure of sampling adequacy $(\mathrm{KMO}=.75$ ) suggest that the model fits the data well (see Hutcheson and Sofroniou 1999).

\subsection{Reliability}

The internal consistency or reliability of each measurement scale is estimated by a Cronbach alpha test with listwise deletion of missing cases. Although most scales are found reliable numerous times in previous research, a Cronbach alpha test is performed on all scales using multiple items. A Cronbach alpha above .70 is generally preferred (see Nunnally 1970). The present study shows that most scales are internally consistent (see Table 3). However, the subscale EO proactiveness showed an initial Cronbach alpha of .61, meaning a lower reliability and internal consistency in the measurement scale than would be deemed preferable. This problem was mainly due to item CE6 and so item CE6 was therefore removed from 
Table 2 Overall exploratory factor analysis model for all multi-item scales

\begin{tabular}{|c|c|c|c|c|}
\hline Item & $\lambda$ & $\lambda$ & $\lambda$ & $\lambda$ \\
\hline \multicolumn{5}{|l|}{ Entrepreneurial orientation innovativeness } \\
\hline CE1-Emphasis on exploitation or exploration & & .71 & & \\
\hline CE2-Number of new lines of products or services marketed & & .82 & & \\
\hline CE3-The impact of changes in product or services & & .80 & & \\
\hline \multicolumn{5}{|l|}{ Entrepreneurial orientation proactiveness } \\
\hline CE4-Reactive or proactive compared to competitors & & .31 & & .73 \\
\hline CE5-Reactive or proactive at introducing new products & & .39 & & .71 \\
\hline CE6-Competitive attitude & & & & .70 \\
\hline \multicolumn{5}{|l|}{ Entrepreneurial orientation risk-taking } \\
\hline CE7-Favorability of low risk or high risk projects & & .27 & 69 & \\
\hline CE8-Exploration intensity & .28 & & .70 & \\
\hline CE9-Reaction to decision-making situations involving uncertainty & & & .89 & \\
\hline \multicolumn{5}{|l|}{ Perceived market turbulence } \\
\hline ENV4-Frequency of changes in marketing practices & .66 & & & .35 \\
\hline ENV5-The rate at which products/services are getting obsolete & .73 & .36 & & \\
\hline ENV6-Predictability of actions of competitors & .72 & & & \\
\hline ENV7-Predictability of demand and taste of consumers & .67 & .33 & & \\
\hline ENV8-Rate of change in modes of production/service & .77 & & & \\
\hline
\end{tabular}

Model fit statistics: $\chi^{2}(d f=91)=686, .15, p=<.001, \mathrm{KMO}=.75$

Factor loadings smaller that .25 have been suppressed

All items were scored from 1 to 7

the measurement scale. This action raised the scale's Cronbach Alpha to an acceptable level of .69.

\subsection{Statistical checks}

Because all data within the present research are collected through the same questionnaire and are self-reported, the observed relationships might be the result of a common measurement source (Podsakoff and Organ 1986; Podsakoff et al. 2003). This measurement error is also know as common method variance and can either inflate or deflate observed relationships between constructs, thus leading to both type one and type two errors. As a post hoc statistical test, a Harman one-factor test is used to check whether common method variance is a potential threat to validity. The existence of common method variance is discovered when a factor emerges that accounts for the majority of the variance, or when a single common factor accounts for the majority of the covariance amongst the variables (see also Podsakoff and Organ 1986). All variables where entered into a factor analysis and the results of the unrotated factor analysis was examined. The Harman one-factor test for common method variance revealed the presence of three distinct factors with eigenvalues greater than one. The three factors combined account for $61.68 \%$ of the total variance. Moreover, the first (largest) factor explains only $29.40 \%$ of the covariance. 
These results suggest that common method variance is not a serious problem within the present study.

\section{Results}

Table 3 gives an overview of all relationships between all constructs used within the present research. It shows that the EO dimensions of innovativeness and risk-taking are not significantly associated with the business performance measure. However, proactiveness is significantly and positively associated with business performance $(p<.05)$.

The perceived market turbulence construct is not significantly related with the business performance measure but it is with the EO dimensions of innovativeness $(p<.01)$ and risk-taking $(p<.01)$. This relationship is shown in prior research (e.g., Covin and Slevin 1989). Surprisingly, proactiveness is not significantly associated with perceived market turbulence. Of the control variables, the number of employees is the only variable that is significantly associated with business performance $(p<.05)$. Firm age and industry are not associated with SME business performance in the correlation analysis.

A listwise hierarchical linear regression analysis $(N=111)$ is applied to test the hypotheses. The control variables were added first, then the independent variables and finally the interaction terms. Checks for multicollinearity were also performed. The tolerance levels of the independent variables vary between .67 and .91 , with an average variance inflation factor (VIF) of 1.08 in model 1, 1.23 in model 2 and 1.34 in model 3; indicating no apparent multicollinearity. The regression analysis can be found in Table 4.

Of the EO variables, only proactiveness has a significant direct positive contribution $(p<.05)$ to SME business performance. This provides support for hypothesis $1 \mathrm{~B}$. The remaining EO dimensions, innovativeness and risk-taking did

Table 3 Means, SD, correlations and reliability for quantitative variables

\begin{tabular}{|c|c|c|c|c|c|c|c|c|c|c|c|}
\hline Variable & $N$ & $M$ & SD & 1 & 2 & 3 & 4 & 5 & 6 & 7 & 8 \\
\hline 1. Firm age & 162 & 43.34 & 34.90 & $(-)$ & & & & & & & \\
\hline 2. No. of employees & 164 & 2.37 & .94 & $.28 * *$ & $(-)$ & & & & & & \\
\hline 3. Manufacturing industry & 134 & .49 & .50 & .17 & .05 & $(-)$ & & & & & \\
\hline $\begin{array}{l}\text { 4. Perceived market } \\
\text { turbulence }\end{array}$ & 152 & 3.45 & 1.11 & -.14 & -.04 & -.09 & $(.80)$ & & & & \\
\hline 5. EO innovativeness & 158 & 3.75 & 1.42 & -.14 & .06 & .01 & $.34 * *$ & $(.79)$ & & & \\
\hline 6. EO proactiveness & 155 & 4.67 & 1.16 & -.05 & .16 & -.06 & .07 & $.41^{* *}$ & $(.69)$ & & \\
\hline 7. EO risk taking & 163 & 3.19 & 1.02 & $-.22 *$ & .02 & -.10 & $.35^{* *}$ & $.34 * *$ & $.23 *$ & $(.75)$ & \\
\hline 8. Performance & 155 & 3.18 & .67 & -.04 & $.23 *$ & -.09 & -.03 & -.02 & $.23 *$ & .05 & $(.87)$ \\
\hline
\end{tabular}

$N$ listwise $=111$. In the diagonal axis the reliabilities (Cronbach's alpha) are shown. For one-item measures Cronbach's alphas cannot be computed, these are labeled (-)

$* * p<.01 . * p<.05$ 
Table 4 Hierarchical regression overall company performance: control variables, universal model and contingency model

\begin{tabular}{|c|c|c|c|c|c|c|}
\hline & \multicolumn{2}{|c|}{ Control variables } & \multicolumn{2}{|c|}{$\begin{array}{l}\text { Universal model, control } \\
\text { variables }\end{array}$} & \multicolumn{2}{|c|}{ Contingency model } \\
\hline & $\beta$ & S.E. & $\beta$ & S.E. & $\beta$ & S.E. \\
\hline Firm age & -.10 & .00 & -.10 & .00 & -.14 & .00 \\
\hline No. of employees & $.26^{* *}$ & .07 & $.23^{*}$ & .07 & .17 & .06 \\
\hline Manufacturing & -.08 & .13 & -.07 & .13 & -.02 & .12 \\
\hline Perceived market turbulence & & & -.01 & .07 & -.04 & .06 \\
\hline EO innovativeness & & & -.15 & .05 & -.14 & .05 \\
\hline EO proactiveness & & & $.24 *$ & .06 & $.30^{* *}$ & .06 \\
\hline EO risk taking & & & .02 & .07 & .05 & .07 \\
\hline Innovativeness $*$ turbulence & & & & & $.34^{* *}$ & .07 \\
\hline Proactiveness $*$ turbulence & & & & & .09 & .07 \\
\hline Risk taking $*$ turbulence & & & & & $-.31^{* *}$ & .08 \\
\hline$R^{2}$ & .07 & & .12 & & .24 & \\
\hline Adjusted $R^{2}$ & .05 & & .06 & & .16 & \\
\hline$\Delta R^{2}$ & $.07 *$ & & .05 & & $.12 * *$ & \\
\hline
\end{tabular}

Standardized regression coefficients are displayed in the table

$* p \leq .05$

$* * p \leq .01$

not have a direct significant relationship with business performance at the time of the study (2009), leading to the rejection of H1A and H1C.

The regression analysis including the interaction terms show that the interaction terms of innovativeness with turbulence $(p<.01)$ are significantly positively related to business performance. This supports hypothesis $2 \mathrm{~A}$. The interaction term of risktaking with turbulence is significant $(p<.01)$ too but, different than expected, the relationship with SME business performance is negative. We therefore reject hypothesis $2 \mathrm{C}$. The data did not support hypothesis $2 \mathrm{~B}$. It is noticeable that the direct relationship of proactiveness with SME business performance is still significant. All the control variables (number of employees, firm age and industry) are not significant in this model.

The regression analysis further shows that the control variables explain $7 \%$ of the variance in SME business performance. After adding the EO variables and perceived market turbulence, the model explains $12 \%$ of the variance in business performance, an additional $5 \%(p=>.10)$. After adding the interaction terms, the model explains $24 \%$ of the variance in performance, an additional $12 \%(p<.01)$.

\section{Discussion}

The goal of this paper was to investigate the influence of EO on SME business performance when such firms face acute market uncertainty and instability. To 
achieve this we collected data during 2009, a year in which many markets were entrenched in turbulence. We sought to examine the impact of an EO on the business performance of SMEs when the skills associated with an EO (e.g., ability to manage uncertainty; innovate to meet emerging opportunities and threats; anticipate the direction of markets; tolerate risk) would theoretically be called for. Our research shows proactiveness is directly related to the performance of the Dutch SMEs under investigation in this study and its effects on business performance is not affected by market turbulence. Innovativeness and risk-taking did show a direct significant relationship with business performance but only when accounting for their interaction with market turbulence. Innovativeness' interaction with market turbulence $(p<.01)$ significantly and positively affected business performance while the interaction term of risk-taking with turbulence was significantly but negatively related to SME business performance.

An explanation for our findings might be found in the financial and economic crisis present in 2009. In uncertain times, like the 2009 crisis, risk-taking, although these are supposed to be calculated risks, may lead to more differentiated returns than under normal economic or positive market circumstances. During the 2009 crisis consumer confidence and spending in the Netherlands dropped significantly (CBS 2010). Often such trauma is responded to within firms by lower R\&D expenditures and delayed introduction of new products which would be sold at premium prices. Our research shows that this strategy should not necessarily be changed (as we had no grounds to support H1A since innovativeness was not directly related to SME performance). But, the research also indicates the shortsighted nature of this action because when high levels of uncertainty or market turbulence are present, firms with higher levels of innovativeness perform better in environments with higher levels of turbulence. In this instance then, the firm will need to have a legacy of innovativeness to draw upon to benefit from turbulence as opposed to building it from new at this time due to the lack of a direct relationship.

Becherer and Maurer (1999) focused on the effect of firms' CEO's proactive behaviour and found that proactiveness was positively and significantly $(\beta=.17$, $p<.01)$ related to change in sales (growth). No significant relationship was found with change in profits. They suggested that "proactive leaders are growing the firm as a strategic approach to the market place" (p. 34), however the lack of significance with profits indicates that "the company needs more refined management" and that "concentrating on a bold, aggressive approach alone may not be sufficient to impact the bottom line" (p. 34). However, our research shows that proactiveness was directly related to our multidimensional measure of business performance and this relationship was not influenced by market turbulence. In line with the results of Hughes and Morgan (2007) from their study of UK firms, it would seem that proactiveness is a cornerstone of the role EO plays in driving firm performance.

Other authors like Covin and Slevin (1989) found that EO was not directly related to performance but only the interaction term with environment. Accordingly, the level of EO should be linked to the environment the firm is operating in. A firm in which the level of EO does not match the level of turbulence in the environment, risks generating inferior business performance, particularly in relation to the risktaking dimension. It is apparent that the effects of EO are not clear cut in relation to 
firm performance or in conditions of increased or acute turbulence. Investments in proactiveness and innovativeness would appear wise under these conditions coupled with a carefully management of the firm's risk taking activities given its negative interaction effect on firm performance when combined with market turbulence. The latter is likely to be due to flawed understanding of uncertainty in the market place caused by increased levels of unpredictability and dynamism (Miller and Friesen 1982). This implies that risk taking needs to be grounded in market intelligent to make better and more calculated risk decisions. With this in mind, a future investigation might want to map the relationship between dimensions of EO and a market orientation (studies have begun to do this but have only done so at the unidimensional level, e.g., Atuahene-Gima and Ko 2001).

In conclusion, although this research did not find a direct positive effect of innovation on performance, it does find that innovative SMEs do perform better in turbulent environments. This is consistent with Miller (1988). In a turbulent market, contrary to our hypothesis, the level of risk-taking is negatively related to SME performance. Earlier in this paper, it is posited that risk-taking, although these are supposed to be calculated risks, may lead to more differentiated returns. This might be due to the acute nature of the 2009 crisis than under normal economic or positive market circumstances. During the 2009 crisis, taking risks does appear to negatively contribute to SME performance. Proactiveness on the other hand shows a consistent and important contribution to firm performance regardless of market turbulence.

\subsection{Practical implications for managers}

The present study highlights the importance of refined strategic management within SMEs. Like Hughes and Morgan (2007), we have to conclude that the blind pursuit of the uniform implementation of EO dimensions is not an effective way to create an advantage. Under turbulent market conditions, innovation seems to be an important way of creating superior performance. However given the negative moderation effects with risk-taking found in this study, we have to conclude that innovation is a very delicate matter. Innovation or the introduction of new products always entails certain levels of risk taking. Under complex situations of market turbulence, innovation still pays off, but these innovative projects should be less risky than under normal market circumstances. SMEs therefore are advised to take calculated risk and should, if possible, delay the introduction of highly risky new products, services or projects, since radical innovation might not be as profitable as under normal market circumstances owing to the negative interaction effect shown by risk-taking and market turbulence on business performance.

Again in line with the findings of Hughes and Morgan (2007), we propose that proactivity is the critical activity, not only for firms in the embryonic stage of firm growth as these authors find, but also for SMEs more broadly as we find herein. Firms profit by having a proactive strategy, regardless of the environment the firm is operating in. Even though our sample has been taken during the 2009 economic crisis, the relationship between EO proactivity and firm performance still holds firm. 


\subsection{Limitations}

Several limitations constrain our findings. The first limitation lies in the sample. Approximately 6,000 Dutch SMEs received an email of which only 201 responded. Although this response rate is not rare for an online survey, it can influence the research results. Due to the inability to send a reminder owing to legal restrictions in doing so, we could not take measures to investigate the possible influences of non response. Second, despite the persistent support found for the use of subjective measures of business performance over 20 years of research (e.g., Dess and Robinson 1984; Wall et al. 2004), it would have been preferable to have had a combination of subjective and objective performance data to assess the broader effects of an EO on firm performance. Objective data was unavailable at the time and firms often do not wish to willingly disclosure objective financial data but nonetheless, such a mix of measures would be preferable. Third it is uncertain how the results found in this research can be generalized to other market situations. Our thesis is that the value of EO might differ between situations of complex or acute market turbulence than what might otherwise be argued as calm or 'normal' market conditions. In fairness, rarely do studies deploy multiple samples at different points in time to gauge such a dynamic. Rather, as is the case here, a measure is used to gauge the perception of market turbulence and volatility facing the firm. In which case, it might have been beneficial to have been able to compare the $\mathrm{EO}$ of firms during 'normal' times and during crisis times so as to study the performance consequences. We did not seek to address the relative advantages of an EO in crisis and non-crisis times herein; rather, we sought to more adequately examine the impact of EO on the business performance of SMEs when the skills associated with entrepreneurship would theoretically be needed. Still, this presents an interesting opportunity for future longitudinal or repeat observation studies. Fourth, similar to almost all research towards the EO-performance relationship, the entrepreneurial orientation scales and the environment scales are perceived measures. During a crisis it might be hard(er) to estimate both. Furthermore there are no studies into this topic as yet. This impedes the ability to fully compare results. A further limitation, and one that tends to afflict most studies of SMEs, is survivor bias. The email survey was only sent to existing companies, but many businesses failed in their first few years and some later in their existence, more so during the study period. We also do not have data for which firms in our sample went on to survive or fail. Indeed, Wiklund and Shepherd (2005) mention the fact that the higher levels of risk that usually comes with entrepreneurial orientation can lead to higher chances of failure. For these reasons the generalizability of the findings presented in this report are somewhat further constrained.

\subsection{Recommendations for further research}

Further research is needed into how firms can build and use relevant organizational capabilities that enable to manage financial and economic crises. Although perceived performance measures are used frequently, the use of archival information in future might be beneficial, given the difficulties in estimating financial results 
during a crisis situation. The fact that the entrepreneurial orientation dimensions vary from each other is not surprising since this is stated empirically earlier (e.g., by Stetz et al. 2000; Kreiser et al. 2002; Hughes and Morgan 2007). But as stated earlier a discussion about whether researchers should treat entrepreneurial orientation as a unidimensional (Miller 1983) or a multi-dimensional construct (Lumpkin and Dess 1996) is still taking place. Although it is mainly theoretical, the results of this research confirm the findings of Covin et al. (2006), who noted that allowing the dimensions to vary enable new and interesting findings to appear. Therefore, it is recommended to use the multidimensional model in further research. At the minimum, the variances in our results suggest that investing in each aspect of EO during a financial and economic crisis, or more generally periods of complex market turbulence, would not appear to be sensible. But its dimensions may have different effects on other aspects of business activity. This possibility offers an intriguing line of future research.

Open Access This article is distributed under the terms of the Creative Commons Attribution Noncommercial License which permits any noncommercial use, distribution, and reproduction in any medium, provided the original author(s) and source are credited.

\section{References}

Antoncic B (2006) Impacts of diversification and corporate entrepreneurship strategy making on growth and profitability: a normative model. J Enterp Cult 14(1):49-63

Antoncic B, Hisrich RD (2001) Intrapreneurship: construct refinement and cross-cultural validation. J Bus Ventur 16(5):495-527

Antoncic B, Hisrich RD (2004) Corporate entrepreneurship contingencies and organizational wealth creation. J Manag Dev 23(6):518-550

Atuahene-Gima K, Ko A (2001) An empirical investigation of the effect of market orientation and entrepreneurship orientation alignment on product innovation. Organ Sci 12(1):54-74

Balkenende JP (2007) Minister-president Balkenende bij 'Nederland Innovatief'. Retrieved 25th Jan 2010, http://www.minaz.nl/Actueel/Toespraken/2007/December/Minister_president_Balkenende_ bij_Nederland_Innovatief

Bamford CE, Dean TJ, McDougale PP (2000) An examination of the impact of initial founding conditions and decisions upon the performance of new bank start ups. J Bus Ventur 15(3):253-277

Barr PS, Glynn MA (2004) Cultural variations in strategic issue interpretation: relating cultural uncertainty avoidance to controllability in discriminating threat and opportunity. Strateg Manag J 25(1):59-67

Becherer RC, Maurer JG (1999) The proactive personality disposition and entrepreneurial behavior among small company presidents. J Small Bus Manag 37(1):28-37

Burgelman RA (1983) Corporate entrepreneurship and strategic management: insights from a process study. Manag Sci 29(12):1349-1364

Buss DM (1987) Selection, evocation, and manipulation. J Pers Soc Psychol 53(6):1214-1221

CBS (2010) Statistisch Bulletin 2010, 06 (66). Statistics Netherlands, Den Haag

Chandler GB, Keller C, Lyon DW (2000) Unraveling the determinants and consequences of an innovationsupportive culture. Entrepreneurship Theory Pract 25(1):59-76

Chattopadhyay P, Glick WH, Huber GP (2001) Organizational actions in response to threats and opportunities. Acad Manag J 44(5):937-955

Chen J, Zhu Z, Anquan W (2005) A system model for corporate entrepreneurship. Int J Manpow 26(6):529-543

Collins JC (2001) Good to great. HarperBusiness, New York 
Covin JG, Slevin DP (1986) The development and testing of an organization-level entrepreneurship scale. In: Ronstadt R, Hornaday JA, Vesper KH (eds) Frontiers of entrepreneurship research 1986. Babson College, Wellesly, pp 628-639

Covin J, Slevin D (1989) Strategic management of small firms in hostile and benign environments. Strateg Manag J 10(11):75-87

Covin JG, Green KM, Slevin DP (2006) Strategic process effects on the entrepreneurial orientation-sales growth rate relationship. Entrepreneurship Theory Pract 30(1):57-81

Dalmeijer M (2009) Nieuw belastingplan stimuleert ondernemerschap. Retrieved 7 Jan 2010 from http://www.ondernemenjuistnu.nl/2009/11/nieuw-belastingplan-stimuleert-ondernemerschap/

Dess GG, Robinson RB (1984) Measuring organizational performance in the absence of objective measures: the case of the privately-held firm and conglomerate business unit. Strateg Manag Rev 5(3):265-273

Dimitratos P, Lioukas S, Carter S (2004) The relationship between entrepreneurship and international performance: the importance of domestic environment. Int Bus Rev 13(1):19-41

European Commission E (2003) SME definition: commission recommendation of 06 May 2003. EU Commission, Brussels

Geringer JM, Hebert L (1991) Measuring performance of international joint ventures. J Int Bus Stud 22(2):249-263

Goosen CJ, de Coning TJ, Smit E (2002) Corporate entrepreneurship and financial performance: the role of management. S Afr J Bus Manag 33(4):21-28

Govindarajan V (1988) A contingency to strategy implementation at the business-unit level: integrating administrative mechanisms with strategy. Acad Manag J 31(4):828-853

Grewal R, Tansuhaj P (2001) Building organizational capabilities for managing economic crisis: the role of market orientation and strategic flexibility. J Mark 65(2):67-80

Hornsby JS, Kuratko DF, Zahra SA (2002) Middle managers' perception of the internal environment for corporate entrepreneurship: assessing a measurement scale. J Bus Ventur 17(3):253-274

Hughes M, Morgan RE (2007) Deconstructing the relationship between entrepreneurial orientation and business performance at the embryonic stage of firm growth. Ind Mark Manag 36(5):651-661

Hughes M, Hughes P, Morgan RE (2007) Exploitative learning and entrepreneurial orientation alignment in emerging young firms: implications for market and response performance. $\mathrm{Br} \mathrm{J}$ Manag 18(4):359-375

Hutcheson G, Sofroniou N (1999) The multivariate social scientist: introductory statistics using generalized linear models. Sage, Thousand Oaks

Ireland RD, Covin JG, Kuratko DF (2009) Conceptualizing corporate entrepreneurship strategy. Entrepreneurship Theory Pract 33(1):19-46

Jantunen A, Puumalainen K, Saarenketo S, Kyläheiko K (2005) Entrepreneurial orientation, dynamic capabilities and international performance. J Int Entrepreneurship 3(3):223-243

Kaiser HF (1960) The application of electronic computers to factor analyses. Educ Psychol Meas 20:141-151

Kaya N (2006) The impact of human resource management practices and corporate entrepreneurship on firm performance: evidence from Turkish firms. Int J Hum Resour Manag 17(12):2074-2090

Kemelgor BH (2002) A comparative analysis of corporate entrepreneurial orientation between selected firms in the Netherlands and the USA. Entrepreneurship Reg Dev 14(1):67-87

Khandwalla P (1977) The design of organizations. Harcourt Brace Janovich, New York

Knight GA (1997) Emerging paradigm for international marketing: the born global firm. Michigan State University, Michigan

Kraus S, Kauranen I, Reschke CH (2011) Identification of domains for a new conceptual model of strategic entrepreneurship using the configuration approach. Manag Res Rev 34(1):58-74

Kreiser PM, Marino LD, Weaver KM (2002) Assessing the psychometric properties of the entrepreneurial orientation scale: a multi-country analysis. Entrepreneurship Theory Pract 26(4):71-95

Krueger NF (2000) The cognitive infrastructure of opportunity emergence. Entrepreneurship Theory Pract 24(3):5-23

Kumar N, Stern LW, Anderson JC (1993) Conducting interorganizational research using key informants. Acad Manag J 36(6):1633-1651

Lin Z, Carley KM (2001) Organizational design and adaptation in response to crises: theory and practice. Academy of Management Conference Best Paper Proceedings 2001, pp 1-7

Lumpkin GT, Dess GG (1996) Clarifying the entrepreneurial orientation construct and linking it to performance. Acad Manag Rev 21(1):135-172 
Lumpkin GT, Dess GG (2001) Linking two dimensions of entrepreneurial orientation to firm performance: the moderating role of environment and industry life cycle. $\mathrm{J}$ Bus Ventur 16(5):429-451

Luthans F, Stewart TI (1977) A general contingency theory of management. Acad Manag Rev 2(2): 181-195

Miller D (1981) Towards a new contingency approach: the search for organizational gestalts. J Manag Stud 18(1):1-26

Miller D (1983) The correlates of entrepreneurship in three types of firms. Manag Sci 29(7):770-791

Miller D (1988) Relating Porter's business strategies to environment and structure: analysis and performance implications. Acad Manag J 31(2):280-308

Miller D, Friesen P (1982) Innovation in conservative and entrepreneurial firms: two models of strategic momentum. Strateg Manag J 3(1):1-25

Morris MH, Kuratko DF, Covin JG (2008) Corporate entrepreneurship and innovation, 2nd edn. Thomson Higher Education, Mason

Naman JL, Slevin DP (1993) Entrepreneurship and the concept of fit: a model and empirical tests. Strateg Manag J 14(2):137-153

Nunnally JC (1970) Introduction to psychological measurement. McGraw-Hill, New York

Podsakoff PM, Organ DW (1986) Self-reports in organizational research: problems and prospects. J Manag 12(4):531-544

Podsakoff PM, MacKenzie SB, Lee J-Y, Podsakoff NP (2003) Common method biases in behavioral research: a critical review of the literature and recommended remedies. J Appl Psychol 88(5):879-903

Rauch A, Wiklund J, Lumpkin G, Frese M (2009) Entrepreneurial orientation and business performance: an assessment of past research and suggestions for the future. Entrepreneurship Theory Pract 33(3):761-787

Sarkar MB, Echambadi RAJ, Harrison JS (2001) Alliance entrepreneurship and firm market performance. Strateg Manag J 22(6-7):701-711

Schumpeter JA (1942) Capitalism, socialism and democracy. Harper and Brothers, New York

Slater M, Narver JC (2000) The positive effect of a market orientation on business profitability: a balanced replication. J Bus Res 48:69-73

Stam W, Elfring T (2008) Entrepreneurial orientation and new venture performance: the moderating role of intra- and extra-industry social capital. Acad Manag J 51(1):97-111

Stetz PE, Howell R, Stewart A, Blair JD, Fottler MD (2000) Multidimensionality of entrepreneurial firmlevel processes: do the dimensions covary? Front Entrepreneurship Res 459-469

Stevens JP (1992) Applied multivariate statistics for the social sciences. Erlbaum, Hillsdale

Stevenson HH, Jarillo-Mossi JC (1986) Preserving entrepreneurship as businesses grow. J Bus Strategy 7(1):10-23

Swierczek FW, Ha TT (2003) Entrepreneurial orientation, uncertainty avoidance and firm performance: an analysis of Thai and Vietnamese SMEs. Int J Entrepreneurship Innov 4(1):46-58

Venkatraman N (1989) Strategic orientation of business enterprises: the construct, dimensionality and measurement. Manag Sci 35(8):941-962

Wall TD, Mitchie J, Patterson M, Wood SJ, Sheehan M, Clegg CW, West M (2004) On the validity of subjective measures of company performance. Pers Psychol 57(1):95-118

Walter A, Auer M, Ritter T (2006) The impact of network capabilities and entrepreneurial orientation on university spin-off performance. J Bus Ventur 21(4):541-567

Wiklund J (1999) The sustainability of the entrepreneurial orientation-performance relationship. Entrepreneurship Theory Pract 24(1):37-48

Wiklund J, Shepherd D (2003) Knowledge-based resources, entrepreneurial orientation, and the performance of small and medium sized business. Strateg Manag J 24(13):1307-1314

Wiklund J, Shepherd D (2005) Entrepreneurial orientation and small business performance: a configuration approach. J Bus Ventur 20(1):71-91

Williams CC, Round J, Rodgers P (2010) Explaining the off-the-book enterprise culture of Ukraine: reluctant or willing entrepreneurship? Int J Entrepreneurship Small Bus 10(2):165-180

Yoo S (2001) Entrepreneurial orientation, environmental scanning intensity, and firm performance in technology-based SMEs. Front Entrepreneurship Res 365-367

Zahra S (1991) Predictors and financial outcomes of corporate entrepreneurship: an exploratory study. J Bus Ventur 6(4):259-286 
Zahra SA (1993) Environment, corporate entrepreneurship, and financial performance: a taxonomic approach. J Bus Ventur 8(4):319-341

Zahra SA, Covin JG (1995) Contextual influences on the corporate entrepreneurship-performance relationship: a longitudinal analysis. J Bus Ventur 10(1):43-59

Zahra SA, Garvis DM (2000) International corporate entrepreneurship and firm performance: the moderating effect of international environmental hostility. J Bus Ventur 15(5/6):469-493 